\title{
Effects of periodontal treatment on primary sjögren's syndrome symptoms
}

Lucas Macedo Batitucci AMBRÓSIO(a) Emanuel da Silva ROVAI(a) Bruno Nunes de FRANÇA(a) Danilo Andrés BALZARINI(a) leda Santos ABREU(a) Sheyla Batista Bologna LOPES(b) Thaís Borguezan NUNES(b) Silvia Vanessa LOURENÇO(b) Sandra Gofinet PASOTO(c) Luciana SARAIVA(a) Marinella HOLZHAUSEN(a)

(a) Universidade de São Paulo - USP, School of Dentistry, Department of Stomatology, Discipline of Periodontology, São Paulo, SP, Brazil.

(b) Universidade de São Paulo - USP, School of Dentistry, Department of Stomatology, Discipline of General Pathology, São Paulo, SP, Brazil.

(c) Universidade de São Paulo - USP, School of Medicine, Division of Rheumatology, São Paulo, SP, Brazil.

Declaration of Interests: The authors certify that they have no commercial or associative interest that represents a conflict of interest in connection with the manuscript.

Support: This research receiving funding from the Support Center for Research in Neoplastic and Non-Neoplastic Salivary Glands.

Corresponding Author:

Marinella Holzhausen

E-mail: marinella@usp.br

DOI: 10.1590/1807-3107BOR-2017.vol31.0008

Submitted: Jun 21, 2016

Accepted for publication: Nov 01, 2016

Last revision: Nov 24, 2016
Abstract: The aim of this longitudinal prospective study was to evaluate the effects of periodontal treatment on the clinical, microbiological and immunological periodontal parameters, and on the systemic activity (ESSDAI) and subjective (ESSPRI) indexes in patients with primary Sjögren's Syndrome (pSS). Twenty-eight female patients were divided into four groups: pSS patients with or without chronic periodontitis (SCP, SC, respectively), and systemically healthy patients with or without chronic periodontitis ( $\mathrm{CP}, \mathrm{C}$, respectively). Periodontal clinical examination and immunological and microbiological sample collection were performed at baseline, 30 and 90 days after nonsurgical periodontal treatment (NSPT). Levels of interleukin IL-1 $\beta$, IL-8 and IL-10 in saliva and gingival crevicular fluid (GCF) were evaluated by ELISA, as well as the expression of Porphyromonas gingivalis (Pg), Aggregatibacter actinomycetemcomitans, (Aa) Tannerella forsythia (Tf), and Treponema denticola (Td), by qPCR. Systemic activity and pSS symptoms were evaluated by ESSDAI and ESSPRI. NSPT resulted in improved periodontal clinical parameters in both SCP and CP groups $(\mathrm{p}>0.05)$. $P g, A a$, and Tf levels decreased after NSPT only in CP patients $(\mathrm{p}<0.05)$. Significantly greater levels of IL-10 in GCF were verified in both SCP and $\mathrm{CP}$ groups $(\mathrm{p}<0.05)$. SCP patients showed increased salivary flow rates and decreased ESSPRI scores after NSPT. In conclusion, NSPT in pSS patients resulted in improved clinical and immunological parameters, with no significant effects on microbiological status. pSS patients also showed increased salivary flow and lower ESSPRI scores after therapy. Therefore, it can be suggested that NSPT may improve the quality of life of pSS patients.

Keywords: Sjögrens Syndrome; Chronic Periodontitis; Cytokines; Salivary Glands.

\section{Introduction}

Primary Sjögren's Syndrome (pSS) is a systemic autoimmune disease mainly characterized by involvement of the exocrine glands, leading to dry mouth or sicca syndrome, ${ }^{1,2}$ with a global prevalence of about 0.04 to $4.8 \%$, and most affecting women between the fourth and fifth decades of life. ${ }^{3}$ Compromised salivary flow and consequent higher dental plaque index are associated with increased prevalence of chronic periodontitis in pSS patients. ${ }^{4,5,6}$ In fact, Celenligil et al. ${ }^{7}$ observed a higher presence 
of serum antibodies against periodontal pathogens such as Aggregatibacter actinomycetemcomitans (Aa) and Porphyromonas gingivalis (Pg) in pSS patients, compared with healthy subjects with severe chronic periodontitis. Interestingly, Lugonja et al. ${ }^{8}$ also found raised serum antibody levels to Prevotella denticola in pSS patients, compared with a non-inflammatory group of patients with osteoarthritis. These findings may be related to a worse response to colonization and infection by these pathogens, which appear to be present in greater number in the subgingival biofilm of pSS patients. There is also a higher concentration of interleukin (IL) 1, IL-8 and IL-10, important cytokines produced by the inflammatory infiltrate of polymorphonuclear leukocytes, in the gingival crevicular fluid (GCF), saliva and peripheral blood of patients with pSS. ${ }^{9,10,11}$ IL- 1 and IL- 8 cytokines stimulate the adhesion and chemotaxis of immune cells in the inflamed area, thereby expanding the inflammatory cascade. ${ }^{9,10}$ It is believed that the greater presence of pro- and anti-inflammatory cytokines in patients with pSS could influence immunological and local inflammatory responses during the course of periodontal disease. ${ }^{9,12}$ On the other hand, Nakamura-Kiyama et al. ${ }^{13}$ demonstrated that the presence of chronic periodontitis could lead to apoptosis of acinar cells of the salivary glands, suggesting that periodontal inflammation could affect local saliva production. This conclusion raises an inquiry into how periodontal disease can affect local and systemic changes in patients with pSS. Hence, we hypothesized that periodontal therapy conducted by eliminating periodontal inflammation could lead to salivary and systemic changes in patients with pSS. Thus, the present study evaluated the effects of nonsurgical periodontal therapy on the clinical, immunological and microbiological parameters of periodontal disease, and on the systemic activity indexes and symptoms of pSS.

\section{Methodology}

\section{Patient selection and study design}

All the patients with pSS and the healthy controls were selected from January to July of 2015 on the premises of the University of São Paulo, São Paulo,
Brazil. The present study was approved by the Ethics Committee of the School of Dentistry of the University of São Paulo (FOUSP), under number 31643114.9.0000.0075, and by the Hospital Ethics Committee of the School of Medicine, University of São Paulo (HCFMUSP), under number 31643114930010068 ; all selected patients and control individuals signed an informed consent form. The study design was prospective, lasting 3 months, followed by non-surgical treatment of periodontal disease in pSS patients, and included healthy control individuals without symptoms of the sicca syndrome (Figure 1).

The patients recruited comprised 14 of the 60 female pSS patients diagnosed according to the classification criteria of the American-European Consensus Group of $2002^{14}$ and the criteria of the American Academy of Rheumatology of 2012,15 aged between 35 and 70 years, and followed up at the Sjögren's Syndrome Service of the Hospital Clinics of the School of Medicine, University of Sao Paulo. The exclusion criteria were as follows: presence of active severe systemic involvement (neurological, pulmonary, renal or vasculitis involvement), smoking, current use of antibiotics or of phenytoin or calcium channel blockers, positive serology for HIV or hepatitis B or C, other autoimmune diseases (such as systemic lupus erythematosus, rheumatoid arthritis or systemic sclerosis), pregnancy or lactation, current chemotherapy and history of periodontal treatment, in the six months preceding the start of the study.

The pSS patients were divided into the following groups: (i) pSS with chronic periodontitis ( $\mathrm{SCP}, \mathrm{n}=7$ ), based on the criteria by López et al., ${ }^{16}$ and (ii) pSS without chronic periodontitis (SC, $n=7$ ). Healthy control women with no symptoms of sicca syndrome were age-matched to the pSS groups, with a maximum of 5 years of difference, and divided into: (iii) control group with chronic periodontitis $(\mathrm{CP}, \mathrm{n}=7)$ and (iv) control group without chronic periodontitis $(C, n=7)$.

\section{Clinical examination}

All patients selected for the study $(n=28)$ were subjected to a clinical examination performed from 8 a.m. to 10 a.m. Periodontal examination was performed using a computerized periodontal 


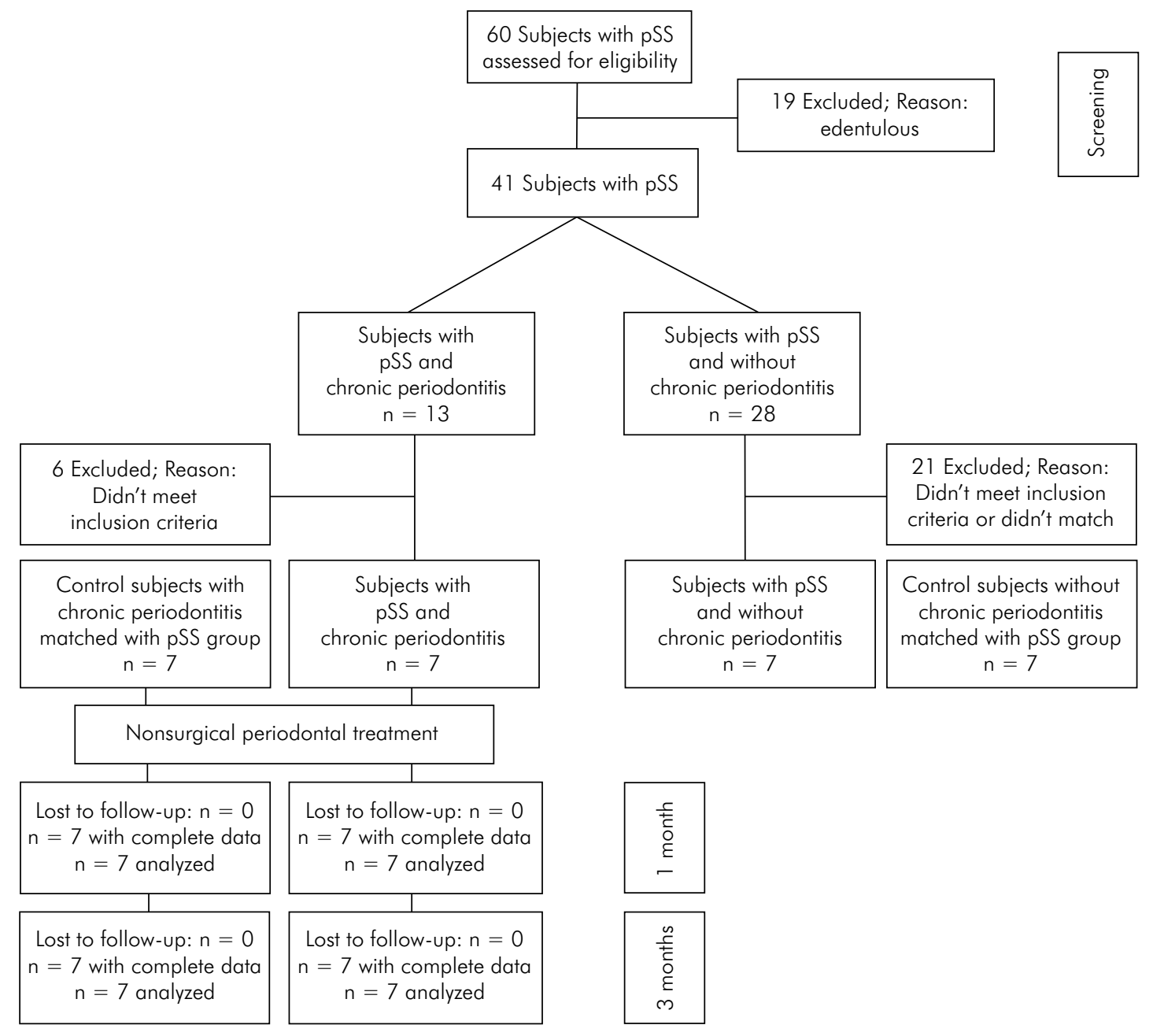

Figure 1. Flow chart of the study design.

probe (Florida $\mathrm{PROBE}^{\circledR}$ version 9. 12. 26) by a calibrated examiner (E.S.R.). Excluding third molars, 6 periodontal sites from all the teeth were evaluated regarding probing depth $(\mathrm{PD})$, clinical attachment level (CAL), bleeding on probing (BOP) and plaque index (PI). ${ }^{17}$

Patients with pSS were also evaluated by a rheumatologist (S.G.P.), who calculated the EULAR Sjögren's syndrome disease activity index (ESSDAI), composed of 12 domains (constitutional, lymphadenopathic, glandular, articular, cutaneous, respiratory, renal, muscular, peripheral nervous system, central nervous system, hematological and biological). ${ }^{18}$

The degree of symptoms was evaluated by calibrated examiners (E.S.R.) and (L.M.B.A.) using the EULAR Sjögren's Syndrome Patient Reported Index (ESSPRI), which is calculated by an arithmetic mean, and composed of 3 domains (dry mouth, fatigue and pain). ${ }^{19}$

\section{Gingival crevicular fluid (GCF) and salivary sample analysis}

The collection of GCF in the periodontal sites of each quadrant followed the criterion of greater PD and/or greater CAL. The teeth were selected after removal of the supragingival bacterial biofilm, isolated using sterile cotton wool rolls and gently dried with directed air jets. Sterile paper strips (Periopaper Strip ${ }^{\circledR}$ Collection, Oraflow, Plainview, NY, USA) were then inserted for 30 seconds. ${ }^{20}$ Samples visibly contaminated with blood were discarded. The volume 
of GCF was analyzed with a Periotron (Periotron 6000, IDE Interstate, Amityville, NY, USA). The strips were then placed on dry ice in microcentrifuge tubes for storage, and later transferred to a freezer kept at $80^{\circ} \mathrm{C}$ for further immunological analysis.

The salivary samples were collected as follows. The patients were instructed to refrain from eating, smoking and drinking 1 hour before the collection. They were asked to rinse their mouth with water for 30 seconds, after which their saliva was collected for 5 minutes and they proceeded to spit their saliva in a flask..$^{21}$ The salivary samples were centrifuged and $200 \mu$ l of the supernatant was stored at $80^{\circ} \mathrm{C}$ for further immunological analysis.

Immunological analysis was performed for IL-1, IL-8 and IL-10 cytokines using specific ELISA kits (R \& D Systems, Minneapolis, MN, USA), according to the manufacturer's protocols.

\section{Microbiological analysis}

The subgingival microbial samples were collected from the same periodontal sites selected for GCF samples. Sterile paper points (Tanariman Ind. LTDA Manaus, AM, Brazil) were inserted to the bottom of the pockets, and then transferred to polypropylene tubes, where they were stored at $-80^{\circ} \mathrm{C}$.

The DNA of the samples was extracted using the Quiamp DNA Mini Kit (Qiagen, Hilden, Germany), according to the manufacturer's instructions. After extraction, the concentration and the purity of the DNA were measured using a spectrophotometer (ND-100 Spectrophotometer ${ }^{\circledR}$, NanoDrop Technologies Inc., Wilmington, DE, USA). The quantification of Porphyromonas gingivalis (Pg), Aggregatibacter actinomycetemcomitans (Aa), Tannerella forsythia (Tf) and Treponema denticola (Td) was made by real-time PCR in a StepOnePLus ${ }^{\mathrm{TM}}$ thermocycler (Applied Biosystems ${ }^{\circledR}$, Foster City, CA, USA), using specific primers. ${ }^{22,23,24}$ The total bacterial load was determined using universal $16 \mathrm{~S}$ rRNA primers. ${ }^{21}$ Standard curves were made using specific $16 \mathrm{~S}$ rRNA genes for each species cloned in the PCR 2.1 TOPO TA ${ }^{\circledR}$ vector (Invitrogen, Carlsbad, CA, USA), diluted from $10^{7}$ to $10^{1}$ copies. The amplification efficiency ranged from 90 to $110 \%$. The qPCR products were detected by fluorescence using the Power SYBR Green PCR Master MIX (Applied Biosystems, Points Birchwood, Warrington, UK) and $2 \mu 1$ of DNA template. The DNA samples and standard dilutions were run in triplicate. The cycles were standardized for each bacterium: $95^{\circ} \mathrm{C} / 15^{\prime \prime}, 65^{\circ} \mathrm{C} / 1^{\prime}, 81^{\circ} \mathrm{C} / 10^{\prime \prime}, 40$ cycles for $\mathrm{Aa}$; $95^{\circ} \mathrm{C} / 15 \ll 60^{\circ} \mathrm{C} / 1<, 81^{\circ} \mathrm{C} / 10^{\prime \prime}, 40$ cycles for Pg; $95^{\circ} \mathrm{C} / 15^{\prime \prime}, 60^{\circ} \mathrm{C} / 1^{\prime}, 74^{\circ} \mathrm{C} / 10^{\prime \prime}, 40$ cycles for Tf; and $95^{\circ} \mathrm{C} / 15 “ 60^{\circ} \mathrm{C} / 1^{\prime}, 83.7^{\circ} \mathrm{C} / 10^{\prime \prime}, 40$ cycles for $\mathrm{Td}$. The levels of each species were expressed as the number of copies of the 16S rRNA gene. An average load of bacteria for each microorganism was calculated for each subject by averaging the microbial values of the four collected sites.

\section{Nonsurgical periodontal treatment}

All patients received adequate instructions of oral hygiene $(\mathrm{IOH})$. Patients diagnosed with chronic periodontitis were referred for nonsurgical periodontal treatment, which was performed by I.S.A. The periodontal treatment consisted of scaling and root planing of the entire mouth using an ultrasound (Cavitron, Dentsply, Chicago, IL, USA) and manual curettes (Hu-Friedy, Chicago, IL, USA) to perform fullmouth scaling (F.M.S.), adapted from Quirynen et al. ${ }^{25}$ Depending on the amount of calculus, the procedure was performed in 2 sessions with a 1week interval.

\section{Clinical reassessment}

After non-surgical periodontal therapy, patients in the SCP and $\mathrm{CP}$ groups were reassessed by calibrated examiners (E.S.R. and L.M.B.A.) for clinical parameters, collection of saliva, GCF and subgingival microbiota samples taken at 30 and 90 days.

\section{Power calculation}

Sample size calculation considered the primary outcome as "salivary flow." Considering a standard deviation of $0.27 \mathrm{ml} / \mathrm{min}$, a level of significance of $5 \%$, a power of $90 \%$ and a 2 -sided test, 13 patients per group would be required to detect a difference of $0.35 \mathrm{ml} / \mathrm{min}$ between Sjögren's subjects and healthy controls. Accordingly, we decided to include 14Sjögren's patients (7 with periodontitis and 7 without periodontitis) and 14 healthy controls ( 7 with periodontitis and 7 without periodontitis). 


\section{Statistical analysis}

The data were analyzed by the Student's paired ttest. The Fisher's exact or chi-square tests were used to evaluate the frequency of variables. Correlation risk analyses were performed using the Pearson linear correlation test. All analyses and graphics of the present study were performed using the GraphPad Prism version 6.0 and Instat 3 statistical programs. A value of $p<0.05$ was considered statistically significant, and the data were presented as \pm mean of the standard deviation (SD).

\section{Results}

\section{Demographic data and periodontal clinical parameters}

The prevalence of edentulism in the group of patients with pSS was $31.66 \%$. Each study group included seven individuals with similar mean age $(p=0.79)$ and socioeconomic status $(p=0.99)($ Table 1$)$.
Table 2 illustrates the overall current therapy, such as the use of artificial saliva and antirheumatic drugs in the SC and the SCP groups. There were no significant changes in the use of medications between the two groups (SC and SCP, $\mathrm{p}>0.05$ ). In addition, the table also reveals that only one patient from the SCP group was given an increased dose of prednisone 30 days after periodontal treatment.

The SC group presented the worst rate of $\mathrm{BOP}$, and the worse PI, compared with the C group $(p=0.01)$. At baseline, there were no significant differences between the SCP and CP group in relation to the periodontal clinical parameters.

Periodontal treatment was effective in the CP group for all periodontal clinical parameters evaluated at 30 days ( $\mathrm{p}<0.05)$, and remained stable at the 90day revaluation. In the SCP group, improvements were also observed for all periodontal clinical parameters during the 30-day trial ( $p<0.05)$, except for CAL $(\mathrm{CAL}, \mathrm{p}=0.46)$, which showed improvement only

Table 1. Demographic characteristics of individuals included in the study.

\begin{tabular}{lcccc}
\hline & \multicolumn{4}{c}{ Group (Mean \pm Standard deviation) } \\
Variable & Control (C) & Chronic periodontitis (CP) & Siögren control (SC) & Siögren with chronic periodontitis (SCP) \\
\hline Gender (male/female) & $0 / 7$ & $0 / 7$ & $0 / 7$ & $0 / 7$ \\
Age (years) & $49 \pm 6.73$ & $53.14 \pm 7.6$ & $52.14 \pm 14.1$ & $53.43 \pm 9.14$ \\
\hline
\end{tabular}

Table 2. Use of artificial saliva and antirheumatic drugs in the primary Siögren's Syndrome Control Group (SC) and the primary Siögren's Syndrome with Chronic Periodontitis Group (SCP).

\begin{tabular}{|c|c|c|c|c|}
\hline \multicolumn{5}{|c|}{ Group (Mean \pm Standard deviation) } \\
\hline \multirow{2}{*}{ Variable } & \multirow{2}{*}{ Siögren Control (SC) } & \multicolumn{3}{|c|}{ Siögren with Chronic Periodontitis (SCP) } \\
\hline & & Baseline & After 30 days & After 90 days \\
\hline Using artificial saliva / Not using & $1 / 6$ & $3 / 4$ & NC & NC \\
\hline DMARDs & 0 & 1 & NC & NC \\
\hline DMARDs + SAIDs & 3 & 1 & $\uparrow \pi \rho \varepsilon \delta v ı \sigma o v \varepsilon$ & NC \\
\hline DMARDs + bisphosphonates & 0 & 1 & NC & NC \\
\hline DMARDs + SAIDs + bisphosphonates & 0 & 1 & NC & NC \\
\hline Antidepressants & 0 & 1 & NC & NC \\
\hline SAIDs & 1 & 0 & NC & NC \\
\hline Bisphosphonates & 1 & 1 & NC & NC \\
\hline Number of participants using medicines / Not using & $5 / 2$ & & $6 / 1$ & \\
\hline
\end{tabular}

NC: no change; DMARDs:disease-modifying antirheumatic drugs: azathioprine, mycophenolate, hydroxychloroquine, methotrexate; SAIDs: steroidal anti-inflammatory drugs: prednisone, bisphosphonates: alendronate; Antidepressants: fluoxetine. 
at the 90day reevaluation $(\mathrm{p}=0.01)$. Interestingly, the SCP group showed further deterioration in PI $(p<0.05)$ at the 90day reevaluation (Table 3$)$.

\section{Salivary analysis}

The SC group showed a significantly lower salivary flow, increased concentration of IL-1ß and IL-8, and lower concentration of IL-10, compared with the C group ( $\mathrm{p}<0.05)$.

At baseline, the SCP group presented decreased salivary flow and increased concentration of IL-1B, compared with the $\mathrm{CP}$ group $(\mathrm{p}<0.05)$. Within the SCP group, there was a significant increase in total unstimulated salivary flow both at the 30 and 90day time points $(\mathrm{p}<0.05)$ (Table 4$)$. Interestingly, there was a negative correlation between salivary flow and PI $(r=-0.21)$.

\section{GCF analysis}

The SC group had a higher concentration of IL-1B in GCF, compared with the C group $(p=0.01)$. Moreover, the SCP group presented a higher amount of GCF volume and lower concentration of IL-10 $(p<0.05)$, compared with the SC group. Similarly, the $\mathrm{CP}$ group presented a greater amount of GCF volume and lower concentration of IL-10 ( $p<0.05)$.

In the $C P$ group, increased IL-10 levels and decreased GCF volume were found $(p<0.05)$ at the 30 day reevaluation; these results were maintained $(p=0.01)$, together with increased levels of IL-8 $(p=0.03)$, at the 90day reevaluation.

In the SPC group, there was a statistically significant increase of IL-10 and decrease in GCF volume $(\mathrm{p}<0.05)$, at the 30 day reevaluation; these results were maintained $(p<0.05)$ at the 90day reevaluation, together with increased levels of IL-1ß $(\mathrm{p}=0.01)($ Table 5).

\section{Assessment of clinical systemic activity and symptoms of pSS}

The presence of chronic periodontitis did not influence the ESSSDAI ( $p>0.05)$. In addition, periodontal treatment did not significantly change the index ( $p>0.05$ ) (Table 6). Regarding the ESSPRI, there was a significant improvement in the SCP group after periodontal treatment, compared with

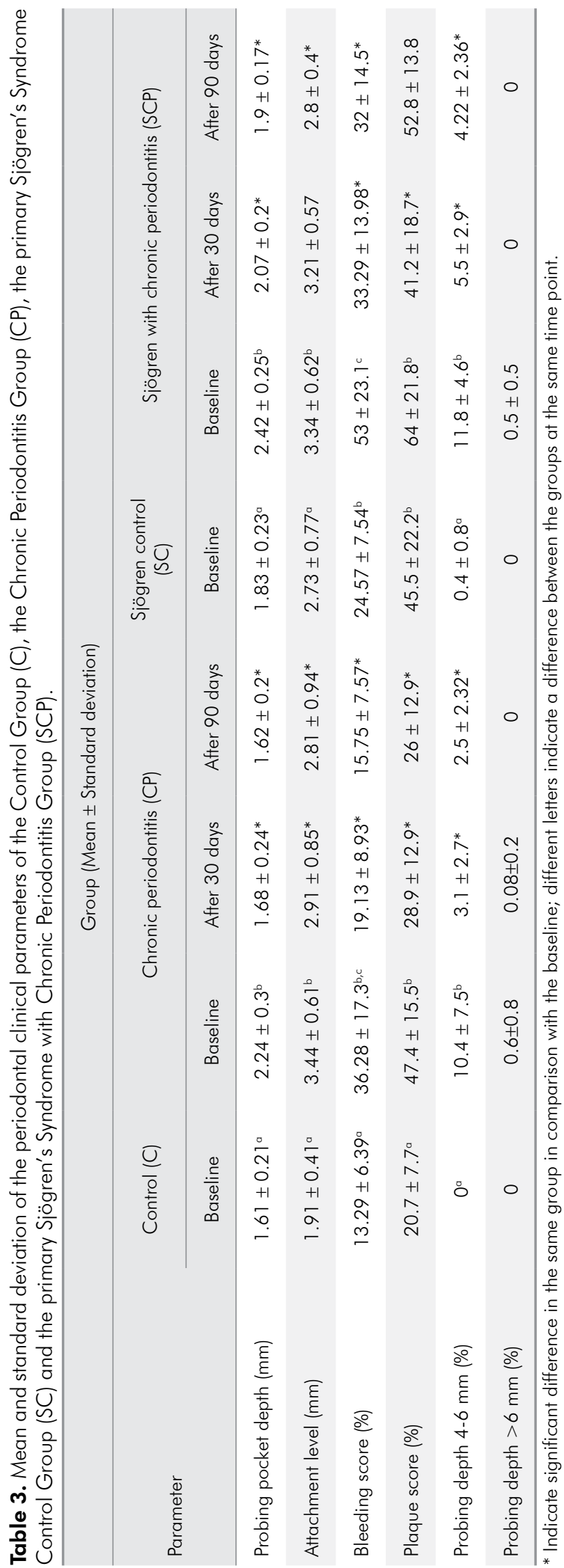


the baseline, both at 30 days and at 90 days $(p=0.03$ and $p=0.04$, respectively) (Table 7).

The ESSDAI was positively correlated with the IL-1 levels $(r=0.58$ and $r=0.27$, saliva and GCF levels, respectively), and the IL-8 levels ( $r=0.47$ and $r=0.50$, salivary and GCF levels, respectively). In addition, there was a weak negative correlation between ESSDAI and salivary flow $(\mathrm{r}=-0.36)$.

The ESSPRI was positively correlated with the ESSDAI $(r=0.31)$, PS $(r=0.46)$, \% of $4-6 \mathrm{~mm}$ pockets $(\mathrm{r}=0.29)$ and the GCF volume $(r=0.26)$. Furthermore, there was a negative correlation between the ESSPRI and both the salivary flow $(r=-0.23)$ and the IL- $1 ß$ fluid levels $(r=-0.38)$. In addition, pain was positively correlated with the PD $(r=0.62)$ and CAL $(r=0.42)$, and fatigue was positively correlated with the PD $(\mathrm{r}=0.26)$ and CAL $(\mathrm{r}=0.27)$.

\section{Microbiological analysis}

In relation to the microbiological samples collected at the periodontal sites at baseline, there were no differences in the number of $\mathrm{Pg}, \mathrm{Aa}, \mathrm{Tf}$ and $\mathrm{Td}$ bacteria, either between the SC and $\mathrm{C}$ groups or the $\mathrm{CP}$ and SCP groups. The periodontal treatment in the $\mathrm{CP}$ group showed a significant decrease in $\mathrm{Pg}$, Aa and Tf bacteria at the 30- and 90day evaluations $(\mathrm{p}<0.05)$ (Table 8).

\section{Discussion}

pSS is an autoimmune disease of unknown etiology and difficult diagnosis. ${ }^{19,26}$ Studies in oral health show that $\mathrm{PSS}$ patients have a diminished salivary flow with consequent high incidence of dental caries, increased susceptibility to oral candidiasis, tooth loss, greater periodontal destruction, pain symptoms during chewing, speech difficulties, tongue palpitation and angular cheilitis. $5,6,27,28,29,30,31,32$

The present study demonstrated that the decreased salivary flow in pSS patients was associated with higher PI, and a significant imbalance between the concentration of pro- and anti-inflammatory cytokines. Furthermore, it was observed that periodontal treatment of pSS patients can lead to increased salivary flow and improved ESSPRI. 


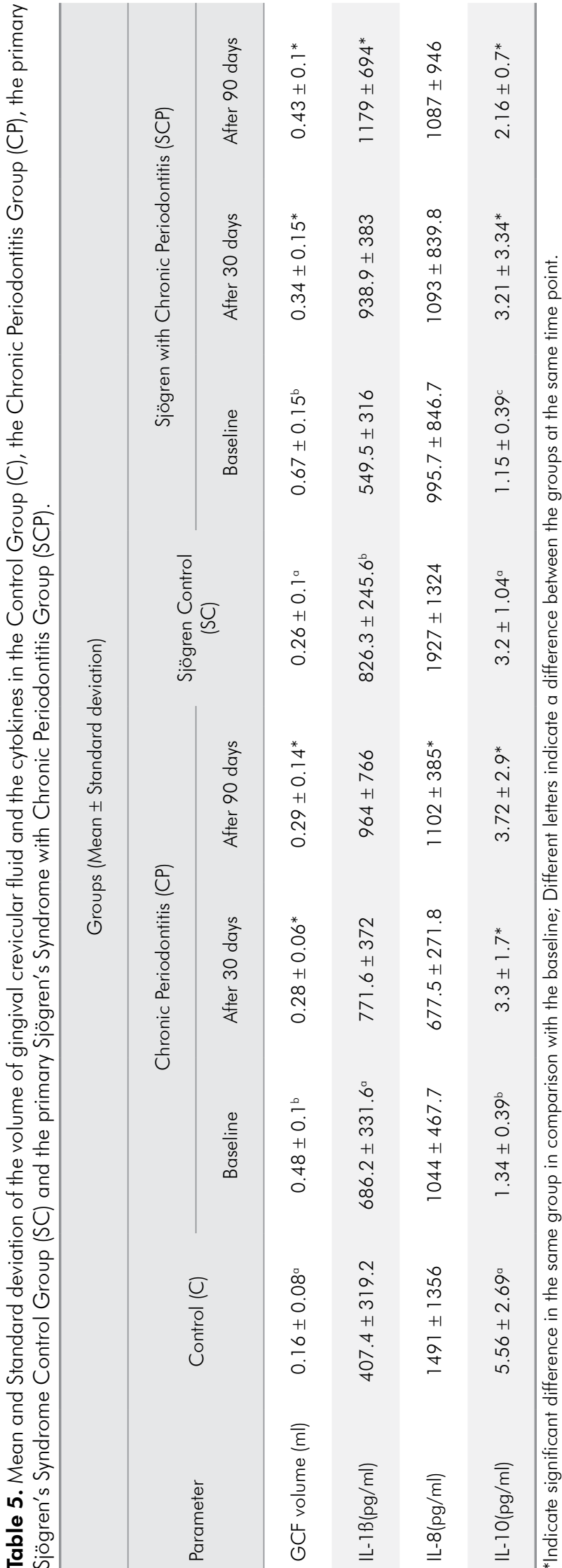

It was also seen that periodontally healthy pSS patients have higher PI and BOP, compared with healthy individuals without periodontitis. Interestingly, Antoniazzi et al. ${ }^{9}$ demonstrated that, regardless of the amount of plaque, patients with pSS have worse gingival indexes, compared with healthy individuals.

In agreement with the findings by Boutsi et al., ${ }^{4}$ our study also showed that patients with pSS and chronic periodontitis have similar clinical periodontal parameters (PD, CAL, BOP, PI), compared with systemically healthy patients with periodontitis at baseline, and after nonsurgical periodontal treatment at 30 and 90 days.

According to Tincani et al., ${ }^{33} \mathrm{pSS}$ patients present a progressive impairment of the salivary glands, with consequent decrease in salivary flow. In the present study, there was an improvement in the salivary flow of pSS patients at 30 and 90 days after periodontal treatment. Similarly, a recent study by Nakamura-Kiyama et al. ${ }^{13}$ showed that, in an experimental model of periodontitis, the removal of the ligature led to an improvement in the salivary flow in rats. The authors of this study suggested that the decrease in periodontal inflammation was associated with improved physiological function of the salivary glands. Interestingly, in the present study, the salivary flow was negatively correlated with probing depth, thus confirming the association of periodontal inflammation with the change in salivary flow.

In the present study, pSS patients showed a pro-inflammatory profile, since they presented greater salivary concentrations of IL- $1 \beta$ and IL-8, and lower concentrations of IL-10, compared with the healthy group. These findings corroborate those of other studies in the literature, which also showed higher concentrations of inflammatory cytokines in the saliva of pSS patients. ${ }^{10,34}$ Interestingly, $\mathrm{Wu}$ et al. ${ }^{35}$ reported that polymorphonuclear neutrophils exposed to the La antigen and anti-La autoantibodies present in autoimmune diseases such as pSS showed increased IL-8 production. Additionally, the present study demonstrated that increased salivary levels of IL-1ß and IL-8 were correlated with lower salivary flow in pSS 
Table 6. Mean and standard deviation of the ESSDAl in the primary Siögren's Syndrome Control Group (SC) at baseline and the primary Siögren's Syndrome with Chronic Periodontitis Group (SCP) at baseline, 30 and 90 days.

\begin{tabular}{lcccc}
\hline & \multicolumn{4}{c}{ Group (Mean \pm Standard deviation) } \\
\cline { 2 - 5 } Parameter & Siögren control & \multicolumn{3}{c}{ Siögren with chronic periodontitis } \\
\cline { 2 - 5 } & Baseline & Baseline & After 30 days & After 90 days \\
\hline ESSDAI & $3.57 \pm 4.23$ & $3 \pm 3.05$ & $2.57 \pm 2.14$ & $2 \pm 1.52$ \\
\hline
\end{tabular}

Table 7. Mean and standard deviation of the ESSPRI in the primary Siögren's Syndrome Control Group (SC) at baseline and the primary Siögren's Syndrome with Chronic Periodontitis Group (SCP) at baseline, 30 and 90 days.

\begin{tabular}{|c|c|c|c|c|}
\hline \multicolumn{5}{|c|}{ Group (Mean \pm Standard deviation) } \\
\hline \multirow{2}{*}{ ESSPRI } & \multirow{2}{*}{$\begin{array}{c}\text { Siögren control } \\
\text { Baseline }\end{array}$} & \multicolumn{3}{|c|}{ Siögren with chronic periodontitis } \\
\hline & & Baseline & After 30 days & After 90 days \\
\hline Dry mouth & $8.42 \pm 1.90$ & $8.14 \pm 1.67$ & $6.28 \pm 3.59$ & $7.42 \pm 2.37$ \\
\hline Fatigue & $5.42 \pm 3.15$ & $7.85 \pm 1.67$ & $5.57 \pm 2.87$ & $6.28 \pm 3.30$ \\
\hline Pain & $5.14 \pm 3.53$ & $6.85 \pm 2.54$ & $5.71 \pm 1.97$ & $5.42 \pm 3.15$ \\
\hline Total & $6.80 \pm 1.89$ & $7.61 \pm 0.89$ & $5.85 \pm 1.30^{*}$ & $6.37 \pm 1.82^{*}$ \\
\hline
\end{tabular}

${ }^{*}$ Indicate significant a difference in the same group in comparison with the baseline.

patients. These findings could be related to the worse response seen in pSS patients in the first 30 days regarding CAL gain, compared with the control group. This local pro-inflammatory profile could somehow hamper the periodontal healing process mechanisms, as suggested by Pers et al., ${ }^{5}$ who observed that $\mathrm{pSS}$ patients had more salivary concentration of B-cell activating factor (BAFF), a TNF family cytokine that could be related to a worse periodontal clinical status.

Furthermore, after periodontal therapy, there was a significant increase in IL-10 levels in the gingival crevicular fluid to levels similar to those of periodontally healthy patients. This increase was moderately correlated with the decrease in the volume of the fluid, in PI and in the percentage of 4 to6mm periodontal pockets. These results corroborate evidence of the anti-inflammatory effects of IL-10 on periodontal tissues. ${ }^{36}$

Microbiological analysis of periodontal sites of pSS patients showed no significant differences, compared with the control groups. These results agree with those by Almståhl et al. ${ }^{31}$, who also found no significant differences regarding the number of periodontopathogens in the periodontal pocket of pSS patients, compared with the control group. Interestingly, periodontal treatment did not result in a significant decrease in the number of bacteria in the pSS group. This suggests that these patients face a greater challenge in controlling these bacteria, and implies that periodontal supportive care should be maintained by frequent recall visits.

It is noteworthy that the present study, within the limits of its related literature search, was the first to assess the subjective and objective clinical response of periodontal treatment on systemic activity and the index of symptoms in pSS patients. Therefore, we suggest that our study may contribute to elucidating a possible two-way relationship between periodontal disease and pSS. Interestingly, we observed a significant improvement in the ESSPRI values after periodontal treatment. In addition, we observed a positive association between the ESSPRI and the clinical probing depth parameter. Importantly, there was a strong correlation between the ESSPRI pain component and the probing depth parameter. The improvement verified in the 


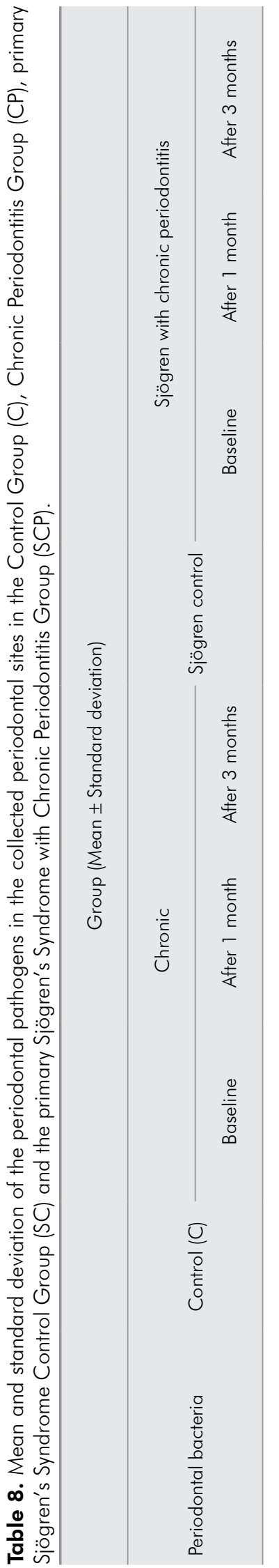

ESSPRI of patients in the present study after periodontal therapy was similar to that found by studies evaluating the effects of using rituximab and abatacept for 4 weeks on disease symptoms. ${ }^{37,38}$ In the present study, we also found a low correlation between the ESSPRI and the ESSDAI indexes $(r=0.31)$; this reinforces the need to associate the assessments of these important indexes in relation to pSS, as pointed out by Seror et al. ${ }^{39}$

Moreover, there were no significant changes in the medications and the dosage along the experimental periods of the present study. Therefore, it can be suggested that the periodontal treatment itself may be the only factor responsible for the improved salivary flow and quality of life of patients with pSS.

The present study had some limitations associated with the small sample size ( $\mathrm{n}=7$ per group) and the short-term followup of 90 days that could have interfered in the main results. Furthermore, since the inclusion and exclusion criteria were strict, the external validity of this study was low; hence, the main findings can be applied only to women with pSS, non-smokers, without HIV or hepatitis B or C, who are not pregnant or lactating, and who are not undergoing chemotherapy.

\section{Conclusions}

The present study concludes that pSS patients present similar periodontal clinical, immunological and microbiological parameters, compared with control individuals both at baseline and after nonsurgical periodontal treatment. In addition, periodontal treatment resulted in a significant improvement in salivary flow and ESSPRI. It can therefore be suggested that periodontal treatment may positively affect the quality of life of pSS patients.

\section{Acknowledgments}

The authors acknowledge the financial support of the SALIVA Research Nucleus of Support (NAP-SALIVA) of the University of São Paulo. M.H. and L.S. currently receive research grants from São Paulo Research Foundation (FAPESP, respectively, 2015/07396-2, and 2013/26381-0). B.N.F and E.S.R. currently receive scholarships from FAPESP (respectively, 2014/06387-7, and 2015/24061-4). 


\section{References}

1. Ramos-Casals M, Brito-Zerón P, Sisó-Almirall A, Bosch X. Primary Sjogren syndrome. BMJ. 2012;344:e3821. doi:10.1136/bmj.e3821

2. Pereira DL, Vilela VS, dos-Santos TCRB, Pires FR. Clinical and laboratorial profile and histological features on minor salivary glands from patients under investigation for Sjögren's syndrome. Med Oral Patol Oral Cir Bucal. 2014;19(3):e237-41. doi:10.4317/medoral.19486

3. Valim V, Zandonade E, Pereira A.M, Filho OHB, Serrano EV, Musso C, et al. Primary Sjögren's syndrome prevalence in a major metropolitan area in Brazil. Rev Bras Reumatol. 2013;53(1):24-34. doi:10.1590/S0482-50042013000100003

4. Boutsi EA, Paikos S, Dafni UG, Moutsopoulos HM, Skopouli FN. Dental and periodontal status of Sjögren's syndrome. J Clin Periodontol. 2000;27(4):231-5. doi:10.1034/j.1600-051x.2000.027004231.x

5. Pers JO, D'Arbonneau F, Devauchelle-Pensec V, Saraux A, Pennec YL, Youinou P. Is periodontal disease mediated by salivary BAFF in Sjögren's syndrome? Arthritis Rheum. 2005;52(8):2411-4. doi:10.1002/art.21205

6. Ergun S, Çekici A, Topcuoglu N, Migliari DA, Külekçi G, Tanyeri $\mathrm{H}$ et al. Oral status and Candida colonization in patients with Sjögren's Syndrome. Med Oral Patol Oral Cir Bucal. 2010;15(2):e310-5. doi:10.4317/medoral.15.e310

7. Celenligil H, Eratalay K, Kansu E, Ebersole JL. Periodontal status and serum antibody responses to oral microorganisms in Sjögren's Syndrome. J Periodontol. 1998;69(5):571-7. doi:10.1902/jop.1998.69.5.571

8. Lugonja B, Yeo L, Milward MR, Smith D, Dietrich T, Chapple IL et al. Periodontitis prevalence and serum antibody reactivity to periodontal bacteria in primary Sjögren's syndrome: a pilot study. J Clin Periodontol. 2016;43(1):26-33. doi:10.1111/jcpe.12485

9. Antoniazzi RP, Miranda LA, Zanatta FB, Islabão AG, Gustafsson A, Chiapinotto GA et al. Periodontal conditions of individuals with Sjögren's syndrome. J Periodontol. 2009;80(3):429-35. doi:10.1902/jop.2009.080350

10. Lee YJ, Scofield RH, Hyon JY, Yun PY, Lee HJ, Lee EY et al. Salivary chemokine levels in patients with primary Sjögren's syndrome. Rheumatology (Oxford). 2010;49(9):1747-52. doi:10.1093/rheumatology/keq121

11. Iwamoto N, Kawakami A, Arima K, Nakamura H, Kawashiri S, Tamai M, et al. Regulation of disease susceptibility and mononuclear cell infiltration into the labial salivary glands of Sjögren's syndrome by monocyte chemotactic protein-1. Rheumatology (Oxford). 2010;49(8):1472-8. doi:10.1093/rheumatology/keq079

12. Roescher N, Tak PP, Illei GG. Cytokines in Sjögren's syndrome. Oral Dis. 2009;15(8):519-26. doi:10.1111/j.1601-0825.2009.01582.x
13. Nakamura-Kiyama MN, Ono K, Masuda W, Hitomi S, Matsuo K, Usui M, et al. Changes of salivary functions in experimental periodontitis model rats. Arch Oral Biol. 2014;59(2):125-32. doi:10.1016/j.archoralbio.2013.11.001

14. Vitali C, Bombardieri S, Jonsson R, Moutsopoulos HM, Alexander EL, Carsons SE et al. Classification criteria for Sjögren's syndrome: a revised version of the European criteria proposed by the American-European Consensus Group Ann Rheum Dis 2002;61(6):554-8. doi:10.1136/ard.61.6.554

15. Shiboski SC, Shiboski CH, Criswell L, Baer A, Challacombe S, Lanfrachi Het al. American college of rheumatology classification criteria for Sjögren syndrome: a data-driven, expert consensus approach in the Sjögren's international collaborative clinical alliance cohort. Arthrits Care Res (Hoboken). 2012;64(4):475-87. doi:10.1002/acr.21591

16. López NJ, Smith PC, Gutierrez J. Periodontal therapy may reduce the risk of preterm low birth weight in women with periodontal disease: a randomized controlled trial. J Periodontol. 2002;73(8):911-24. doi:10.1902/jop.2002.73.8.911

17. O'Leary TJ, Drake RB, Naylor JE. The plaque control record. J Periodontol 1972;43(1):38. doi:10.1902/jop.1972.43.1.38

18. Seror R, Ravaud P, Bowman SJ, Baron G, Tzioufas A, Theander E et al. EULAR Sjogren's syndrome disease activity index: development of a consensus systemic disease activity index for primary Sjogren's syndrome. Ann Rheum Dis. 2010;69(6):1103-9. doi:10.1136/ard.2009.110619

19. Seror R, Ravaud P, Mariette X, Bootsma H, Theander E, Hansen A et al. EULAR Sjogren's Syndrome Patient Reported Index (ESSPRI): development of a consensus patient index for primary Sjögren's syndrome. Ann Rheum Dis. 2011;70(6):968-72. doi:10.1136/ard.2010.143743

20. Oliveira APL, Faveri M, Gursky LC, Mestnik MJ, Feres M, Haffajee AD et al. Effects of periodontal therapy on GCF cytokines in generalized aggressive periodontitis subjects. J Clin Periodontol. 2012;39(3):295-302. doi: 10.1111/j.1600-051X.2011.01817.x

21. Bassoukou IH, Nicolau J, Santos MT. Saliva flow rate, buffer capacity, and $\mathrm{pH}$ of autistic individuals. Clin Oral Investig. 2009;13(1):23-27. doi:10.1007/s00784-008-0209-5

22. Shelburne CE, Prabhu A, Gleason RM, Mullally BH, Coulter WA. Quantitation of Bacteroides forsythus in subgingival plaque comparison of immunoassay and quantitative polymerase chain reaction. J Microbiol Methods. 2000;39(2):97-107. doi:10.1016/S0167-7012(99)00106-2

23. Rudney JD, Chen R, Pan Y. Endpoint quantitative PCR assays for Bacteroides forsythus, Porphyromonas gingivalis, and Actinobacillus actinomycetemcomitans. J Periodontal Res. 2003;38(5):465-70. doi:10.1034/j.1600-0765.2003.00670.x 
24. Ramseier CA, Kinney JS, Herr AE, Braun T, Sugai JV, Shelburne CA et al. Identification of pathogen and host-response markers correlated with periodontal disease. J Periodontol. 2009;80(3):436-46. doi:10.1902/jop.2009.080480

25. Quirynen M, Mongardini C, Soete M, Pauwels M, Coucke W, Eldere J. The rôle of chlorhexidine in the one-stage full-mouth disinfection treatment of patients with advanced adult periodontitis: long-term clinical and microbiological observations. J Clin Peridontol. 2000;27(8):578-89. doi:10.1034/j.1600-051x.2000.027008578.x

26. Kramer JM. Current concepts in Sjögren's syndrome and considerations for dental practitioner. N Y State Dent J. 2015;81(1):24-9.

27. Olate S, Muñoz D, Neumann S, Pozzer L, Cavalieri-Pereira L, Moraes M. A descriptive study of the oral status in subjects with Sjögren's syndrome. Int J Clin Exp Med. 2014;7(4):1140-4.

28. Najera MP, al-Hashimi I, Plemons JM, Rivera-Hidalgo F, Rees TD, Haghighat $\mathrm{N}$ et al. Prevalence of periodontal disease in patients with Sjögren's syndrome. Oral Surg Oral Med Oral Pathol Oral Radiol Endod. 1997;83(4):453-7. doi:10.1016/S1079-2104(97)90144-X

29. Lu MC, Jheng CH, Tsai TY, Koo M, Lai NS. Increased dental visits in patients prior to diagnosis of primary Sjögren's syndrome: a population-based study in Taiwan. Rheumatol Int. 2014;34(11):1555-61. doi:10.1007/s00296-014-3003-5

30. Belenguer R, Ramos-Casals M, Brito-Zerón P,Pino J, Sentís J, Agriló $\mathrm{S}$ et al. Influence of clinical and immunological parameters on the health-related quality of life of patients with primary Sjögren's syndrome. Clin Exp Rheumatol. 2005;23(3):351-6.

31. Almståhl A, Kroneld U, Tarkowski A, Wikström M. Oral microbial flora in Sjögren's syndrome. J Rheumatol. 1999;26(1):110-4.
32. Manoussakis MN, Moutsopoulos HM. Sjögren's syndrome current concepts. Adv Intern Med. 2001;47:191-217.

33. Tincani A, Andreoli L, Cavazzana I, Doria A, Favero M, Fenini MG. Novel aspects of Sjögren's syndrome in 2012. BMC Med. 2013;11(1):93. doi:10.1186/1741-7015-11-93

34. Brookes SM, Cohen SB, Price EJ, Webb LM, Feldmann M, Maini RN et al. T cell clones from a Sjogren's syndrome salivary gland biopsy produce high levels of IL-10. Clin Exp Immunol. 1996;103(2):268-72. doi:10.1046/j.1365-2249.1996.d01-623.x

35. Wu CH, LI KJ, Yu CL, Tsai CY, Hsieh SC. Sjögren's syndrome antigen $\mathrm{B}$ acts as an endogenous danger molecule to induce interkeulin- 8 gene expression in polymorphonuclear neutrophils. PLoS One. 2015;10(4):e012550. doi:10.1371/journal.pone.0125501

36. Goutoudi P, Diza E, Arvanitidou M. Effect of periodontal therapy in crevicular fluid interleukin-1 beta and interleukin-10 levels in chronic periodontitis. J Dent. 2004;32(7):511-20. doi:10.1016/j.jdent.2004.04.003

37. Meiners PM, Arends S, Brouwer E, Spijkervet FKL, Vissink A, Bootsma H. Responsiveness of disease activity indices ESSPRI and ESSDAI in patients with primary Sjögren's syndrome treated with rituximab. Ann Rheum Dis. 2012;71(8):1297-302. doi:10.1136/annrheumdis-2011-200460

38. Meiners PM, Vissink A, Kroese FG, Spijkervet FK, Smitt-Kamminga NS, Abdulahad WH et al. Abatacept treatment reduces disease activity in early primary Sjögren's syndrome (open-label proof of concept ASAP study). Ann Rheum Dis. 2014;73(7):1393-6. doi:10.1136/annrheumdis-2013-204653

39. Seror R, Theander E, Bootsma H, Bowman SJ, Tzioufas A, Gottenberg JE et al. Outcome measures for primary Sjögren's syndrome: a comprehensive review. J Autoimmun. 2014;51:51-6. doi:10.1016/j.jaut.2013.12.010 